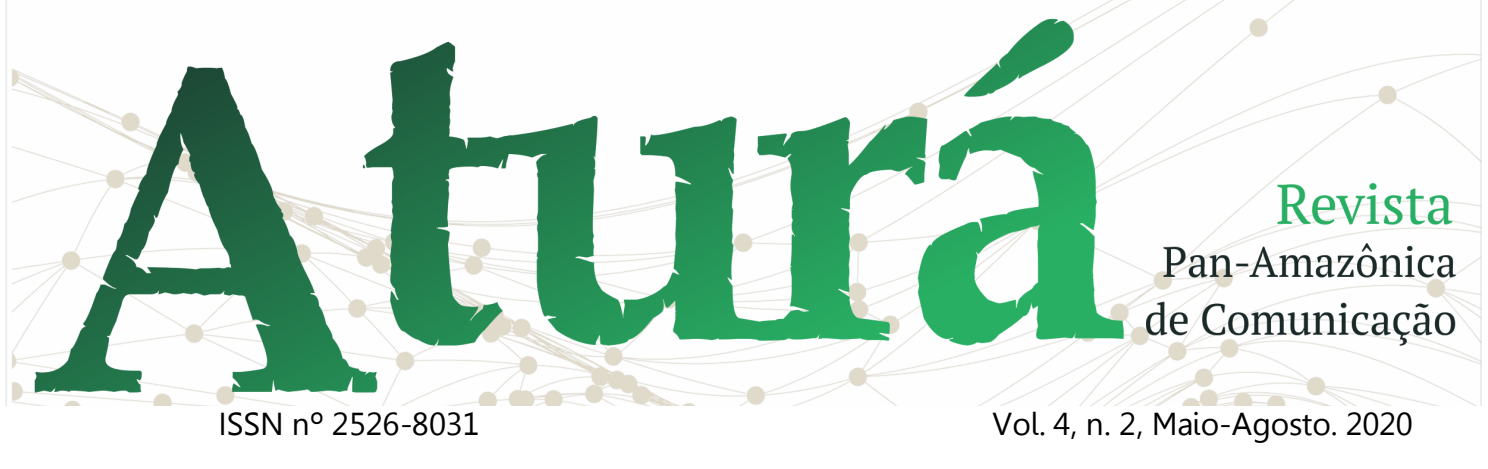

DOI: http://dx.doi.org/10.20873/uft.2526-8031.2020v4n2p19

\title{
IMPACTOS DA PANDEMIA COVID 19 NA VIDA ACADÊMICA DOS ESTUDANTES DO ENSINO A DISTÂNCIA NA UNIVERSIDADE FEDERAL DO TOCANTINS
}

Impacts of the Covid 19 pandemic on the academic life of distance learning students at the Federal University of Tocantins

Impactos de la pandemia de Covid 19 en la vida académica de los estudiantes de educación a distancia en la Universidad Federal de Tocantins

Elaine Jesus Alves, Universidade Federal do Tocantins ${ }^{1}$ Fábio de Jesus Castro, Universidade Federal do Tocantins ${ }^{2}$ Idemar Vizolli, Universidade Federal do Tocantins ${ }^{3}$ Moisés de Souza Arante Neto, Universidade Federal do Tocantins ${ }^{4}$ Suzana Gilioli da Costa Nunes, Universidade Federal do Tocantins ${ }^{5}$

\section{RESUMO}

Este artigo apresenta resultados de informações obtidas junto a estudantes de graduação de cursos da modalidade de educação a distância (EaD) da UFT. A necessidade do estudo se deu a partir da constatação da ausência virtual de muitos estudantes, evidenciada pela falta da postagem de atividades no prazo estabelecido pelos professores ou pela baixa

\footnotetext{
${ }^{1}$ Doutora em Educação. Professora colaboradora no Programa de Pós-Graduação em Comunicação e Sociedade (UFT)..E-mail: elainealves@uft.edu.br.

2 Doutor em Ciências. Professor no curso de Nutrição da Universidade Federal do Tocantins (UFT). E-mail: fabiojcastro@uft.edu.br.

${ }^{3}$ Doutor em Educação. Professor e orientador de pós-graduação na Universidade Federal do Tocantins (UFT). E-mail: idemar@uft.edu.br.

4 Doutor em Ciências dos Materiais. Professor na Universidade Federal do Tocantins (UFT). E-mail: netomoises@uft.edu.br.

5 Doutora em Administração de Empresas. Professora da Universidade Federal do Tocantins (UFT). E-mail: suzanagilioli@yahoo.com.br.
} 


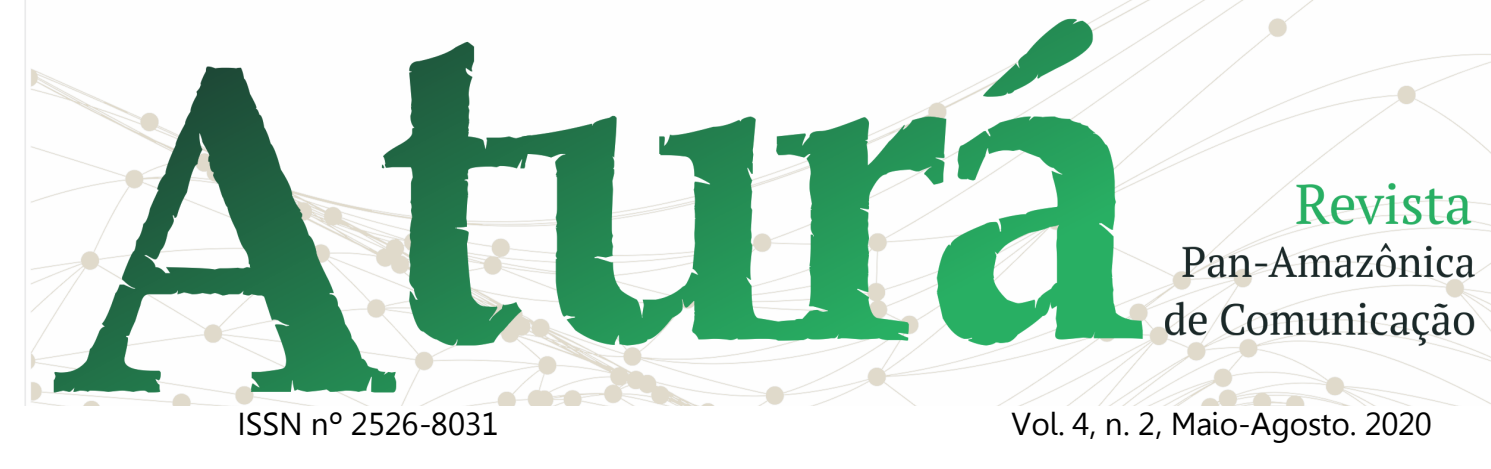

DOI: http://dx.doi.org/10.20873/uft.2526-8031.2020v4n2p19

frequência de acesso ao Moodle. Considerando a situação de Pandemia de COVID-19 que se estende há mais de três meses, levantou-se a hipótese de que os estudantes da EaD e/ou seus familiares, poderiam estar com problemas de saúde, dificuldades financeira e/ou mesmo distúrbios de ordem emocional, e, por consequência, afetando seu desempenho acadêmico. Neste sentido, foi elaborado um instrumento para obter informações que permitissem obter um panorama da situação dos estudantes e, ao mesmo tempo, auxiliasse a pensar em estratégias de acolhimento, atenção, apoio e ajuda pedagógica, inclusive aos professores. As perguntas foram disponibilizadas em formulário online. No universo de 907 estudantes, 241 responderam o questionário. Os resultados indicam que os estudantes tiveram sua vida pessoal e acadêmica afetada pela pandemia.

PALAVRAS-CHAVE: Estudantes; Educação a Distância; Pandemia COVID 19; Presença social.

\section{ABSTRACT}

This article presents results of information obtained from undergraduate students of distance education courses (distance education) at UFT. The need for the study was based on the observation of the virtual absence of many students, evidenced by the lack of posting activities within the period established by the teachers or by the low frequency of access in Moodle. Considering the Pandemic situation by COVID-19 that has been going on for more than three months, the hypothesis was raised that EaD students and / or their family members, could be with health problems, financial difficulties and / or even disorders of emotional order, and, consequently, affecting their academic performance. In this sense, an instrument was developed to obtain information that would provide an overview of the students' situation and, at the same time, help them to think of welcoming, attention, support and pedagogical help strategies, including teachers. The questions were made available on an online form. In the universe of 907 students, 241 answered the questionnaire. The results indicate that students had their personal and academic lives affected by the pandemic.

KEYWORDS: Students; Distance Education; COVID-19 Pandemic; Social presence.

\section{RESUMEN}

Este artículo presenta los resultados de la información obtenida de estudiantes universitarios de cursos de educación a distancia (educación a distancia) en UFT. La necesidad del estudio surgió de la observación de la ausencia virtual de muchos estudiantes, evidenciada por la falta de actividades de publicación dentro del período establecido por los maestros o por la baja frecuencia de acceso en Moodle. Teniendo en cuenta la situación de pandemia de COVID-19 que ha estado ocurriendo durante más de 


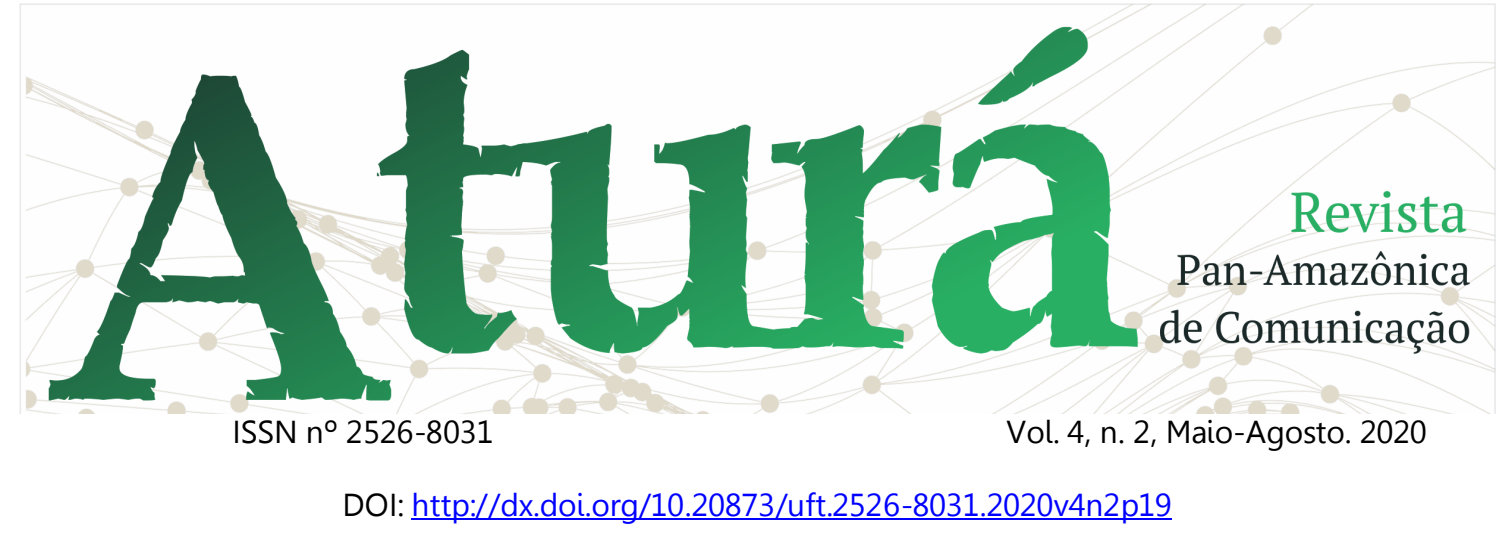

tres meses, se planteó la hipótesis de que los estudiantes de EaD y / o sus familiares, podrían tener problemas de salud, dificultades financieras y / o incluso trastornos de orden emocional $y$, en consecuencia, afectando su rendimiento académico. En este sentido, se desarrolló un instrumento para obtener información que proporcionaría una visión general de la situación de los estudiantes y, al mismo tiempo, los ayudaría a pensar en estrategias de acogida, atención, apoyo y ayuda pedagógica, incluidos los docentes. Las preguntas se pusieron a disposición en un formulario en línea. En el universo de 907 estudiantes, 241 respondieron el cuestionario. Los resultados indican que los estudiantes tuvieron sus vidas personales y académicas afectadas por la pandemia.

PALABRAS CLAVE: Estudiantes; Educación a distancia; Pandemia COVID 19; Presencia social.

Recebido em: 12.02.2020. Aceito em: 14.04.2020. Publicado em: 01.05.2020. 


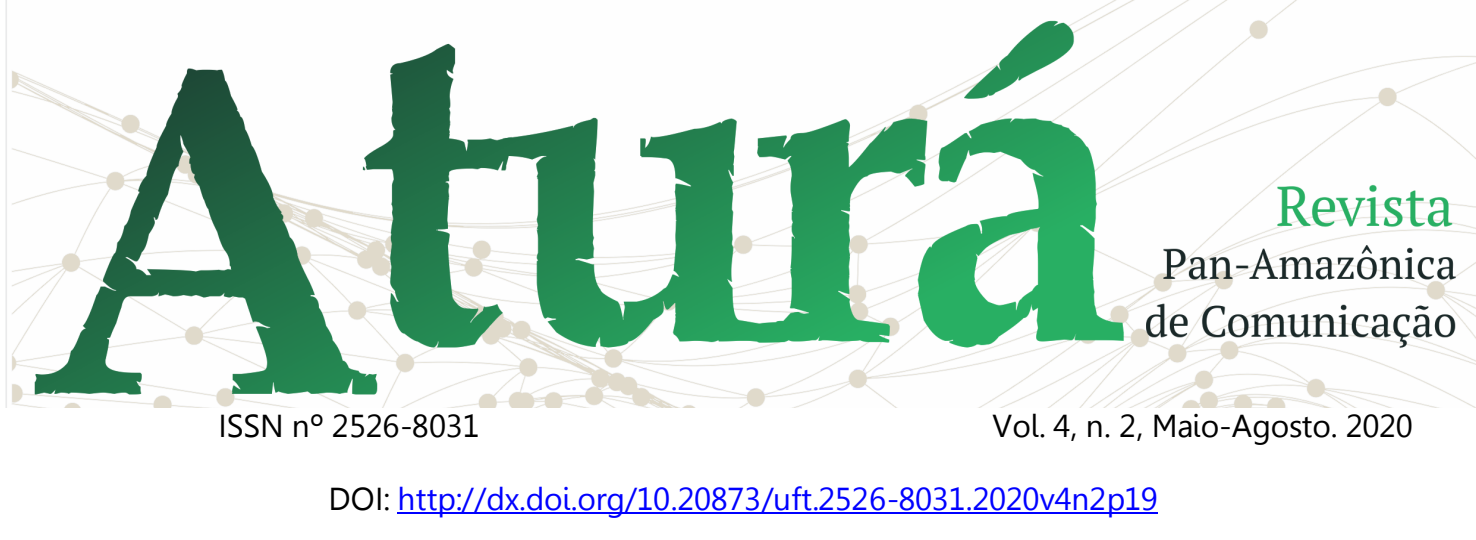

\section{Introdução}

Os efeitos da pandemia ocasionada pelo COVID-19 afetou a humanidade de forma perturbadora, alcançando o ensino superior brasileiro. Das 69 universidades públicas do país, 54 tiveram suas aulas suspensas, totalizando mais de 870 mil estudantes com estudos interrompidos. No entanto, muitas universidades que oferecem cursos na modalidade a distância não suspenderam as aulas, como é o caso da Universidade Federal do Tocantins (UFT). Estudos recentes mostram que em situação de pandemia, além das preocupações em relação à saúde física, os indivíduos passam por

sofrimento psicológico (SCHMIDT, 2020), também distúrbios de cognição e comportamento (COSTA et. al. 2020). As mudanças curriculares e de metodologias de ensino remoto também afetaram o desempenho acadêmico dos estudantes (SAINZ, SAINZ, CAPILLA, 2020).
A partir do início do isolamento social, a Coordenação Pedagógica da Diretoria de Tecnologia Educacional (DTE) da UFT, realizou monitoramento nas salas virtuais a fim verificar o andamento do desenvolvimento das atividades dos cursos na modalidade $\mathrm{EaD}$ e percebeu que muitos estudantes não estavam acessando o Ambiente Virtual de Aprendizagem (AVA) e, por consequência, não postavam as atividades. Situação essa que sensibilizou a equipe pedagógica para a necessidade de atenção e acolhimento, o que levou a realizar uma consulta a fim de elaborar um mapeamento das condições de vida, de saúde e bem estar dos estudantes e de seus familiares, bem como em relação a seu desempenho acadêmico, especialmente durante a pandemia.

\section{Percorrendo trilhas}

Trata-se de uma pesquisa de natureza qualitativa e quantitativa. Embora tenhamos quantificado grande parte dos dados a fim de produzir 


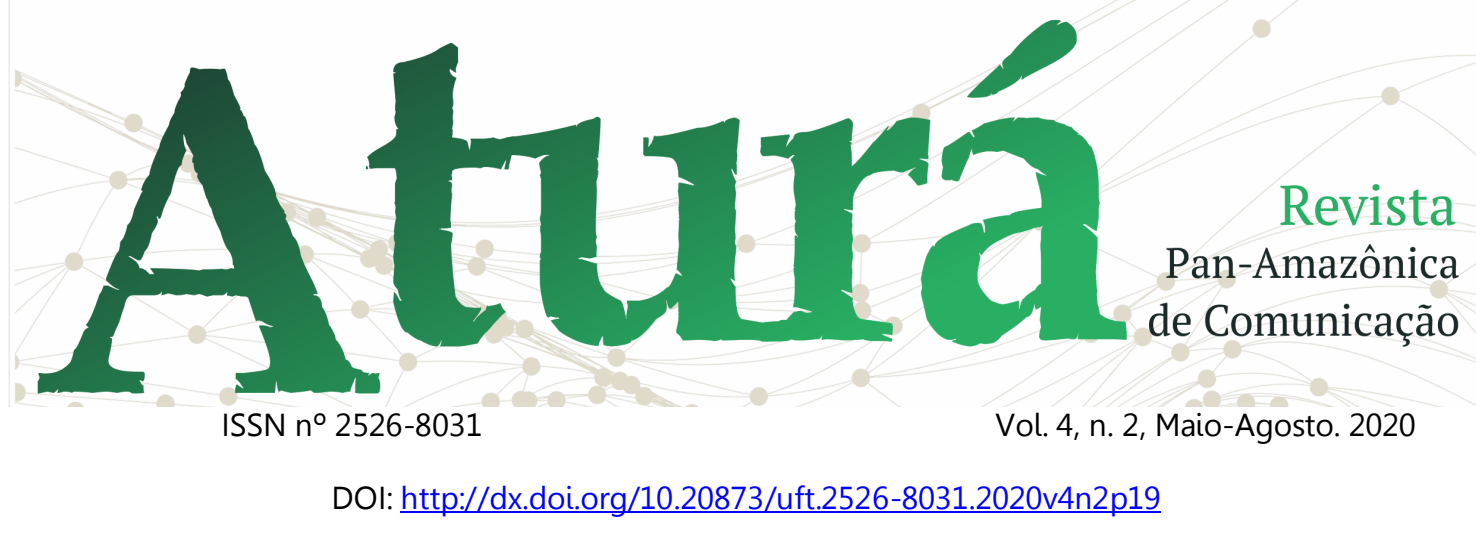

informações tangíveis à situação vivenciada pelos estudantes, algumas questões abertas deram oportunidade dos respondentes apresentarem sua realidade. Nos termos de Godoy (1995), as pesquisas qualitativas requerem que os fenômenos sejam minuciosamente analisados a fim de produzir informações mais fiéis possíveis da realidade.

\begin{abstract}
Um fenômeno pode ser melhor compreendido no contexto em que ocorre e do qual é parte, devendo ser analisado numa perspectiva integrada. (...), enquanto exercício de pesquisa, não se apresenta como uma proposta rigidamente estruturada, ela permite que a imaginação e a criatividade levemos investigadores a propor trabalhos que explorem novos enfoques. (GODOY, 1995, p. 21).
\end{abstract}

Para realizar a pesquisa valemonos de um instrumento de coleta de dados elaborado no Google Forms, composto com vinte questões, sendo três abertas e as demais fechadas de múltipla escolha, capazes de gerar informações acerca da realidade vivenciada pelos estudantes.

A primeira parte do formulário consta de questões sobre o perfil socioeconômico e situação de saúde dos estudantes e seus familiares, assim como em relação a seu desempenho acadêmico no período da pandemia. Um segundo bloco de questões trata de locais para estudo e acesso a equipamentos tecnológicos e internet. O último bloco de perguntas versa sobre o desempenho acadêmico do estudante, condições de estudo e acompanhamento institucional durante a pandemia.

Do universo de 907 estudantes matriculados nos cursos de graduação EaD/UFT, 26,57\% (241) responderam o questionário. Para Lejano (2006), um fenômeno só pode ser entendido por alguém que tenha experimentado ou vivido no contexto dos fatos. O que nos leva a supor que as respostas desse quantitativo de estudantes nos fornece o panorama da realidade vivenciada por eles neste momento de pandemia.

\section{Um panorama em relação a EaD}

A educação mediada por tecnologias tem sido apontada com uma alternativa à formação de professores, considerando que o Brasil, um país com 


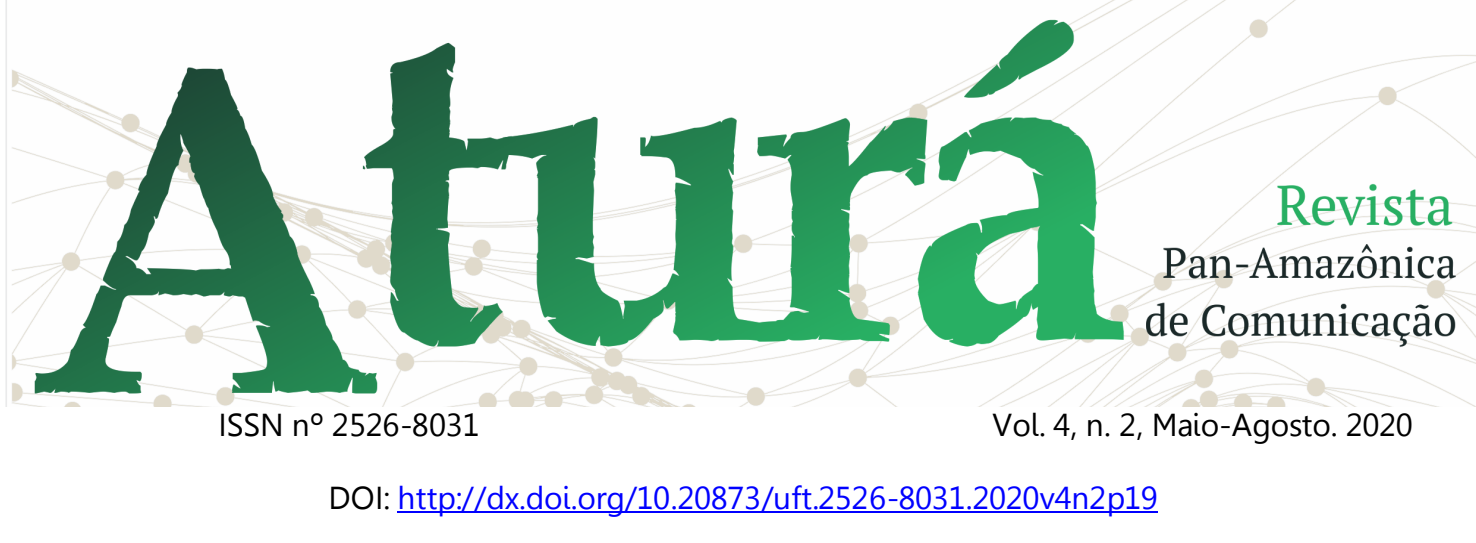

extensão continental, apresenta uma distribuição desigual de acesso ao ensino superior com contrastes relevantes entre regiões com crescimento industrial e nível de vida equivalente ao do Primeiro Mundo e outras regiões de extremo atraso e miséria (BECKER, MARQUES, 2002). Neste sentido, a UFT, ciente do seu papel social em atingir o maior número de pessoas com educação de qualidade, tem aderido ao uso de tecnologias de informação e comunicação para mediar a aprendizagem em espaços e tempos diferentes desde 2005 com a oferta do curso de Biologia a distância.

Dados recentes do IBGE (2018), revelaram que $71,5 \%$ dos domicílios tocantinenses possuem acesso à internet e dentre os dispositivos mais usados para utilizar a rede está o aparelho celular (presente em 99,1\% dos domicílios do estado). Embora a pesquisa destaque um aumento no número de domicílios com internet, existe um percentual considerável de 28,5\% de domicílios que ainda não fazia uso da rede, em 2018. Os três motivos destacados pelos

respondentes da pesquisa para justificar a ausência de internet foram: falta de interesse em acessar (34,1\%), nenhum morador sabia usar a internet $(23,2 \%)$ e serviço de acesso era caro (19,3\%). No Tocantins há ainda problemas relacionados com a qualidade do acesso e falta de portas de conexão em algumas cidades do interior. Logo, o desafio da UFT vai além de promover cursos de formação inicial e continuada mediados por tecnologias no estado, mas lidar com as dificuldades de infraestrutura, de acesso e qualidade da internet na região (ALVES, 2017).

Os cursos na modalidade a distância na Universidade Federal do Tocantins fazem parte do Programa Universidade Aberta do Brasil (UAB). Este programa foi instituído pelo Decreto 5.800, de 8 de junho de 2006 e trata-se de uma política pública de articulação com a Coordenação de Aperfeiçoamento de Pessoal de Nível Superior - CAPES, com vista à expansão da educação superior no âmbito do Plano de Desenvolvimento da Educação. A UAB 


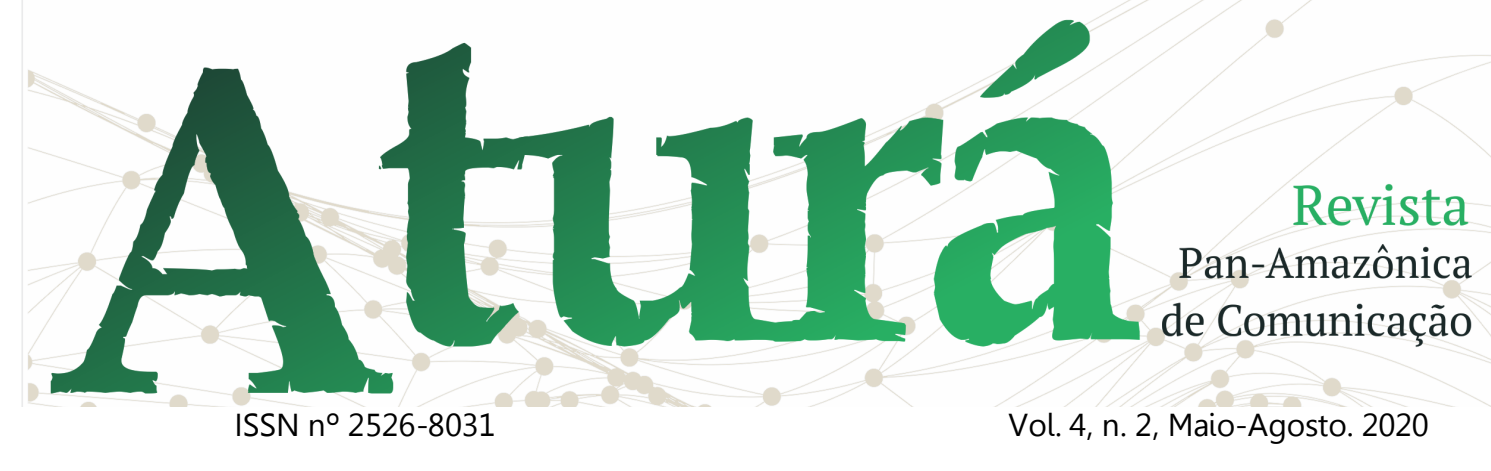

DOI: http://dx.doi.org/10.20873/uft.2526-8031.2020v4n2p19

não é uma instituição de ensino a distância, antes constitui um órgão articulador das instituições públicas responsáveis pela oferta de cursos superiores públicos a distância. Essa articulação estabelece qual instituição de ensino deve ser responsável por ministrar determinado curso em certo município ou certa microrregião por meio dos polos de apoio presencial. A UAB é responsável pelo financiamento e a avaliação, enquanto a gestão acadêmica e operacional está a cargo das instituições públicas de ensino.

Atualmente a UFT oferta cinco cursos de graduação no âmbito da $U A B$, sendo um de bacharelado e quatro licenciaturas nos quais estão matriculados 907 estudantes distribuídos em 23 polos nos municípios tocantinenses. Os polos de apoio presencial são fundamentais no modelo de educação a distância da UAB. $O$ aluno deve estar presente nos finais de semana no polo para o desenvolvimento das atividades presenciais, com frequência mínima de $75 \%$, e durante a semana ele desenvolverá as atividades a distância propostas pelo professor da disciplina. De acordo com o Projeto Político Pedagógico (PPC) do curso de Física EaD (UFT, 2009, p. 32):

As atividades presenciais serão
desenvolvidas pelo tutor presencial,
orientado pelo professor da disciplina, por
meio do material impresso,
videoconferência, web, ou mesmo em
uma visita do docente ao polo. As
atividades a distância, serão
acompanhadas preferencialmente pelo
tutor a distância, podendo também ser
orientado pelo tutor presencial,
supervisionado pelo professor da
disciplina. Essas atividades desenvolvidas
a distância serão sequência das atividades
desenvolvidas presencialmente e devem
ocorrer por meio das mesmas mídias
usadas nas atividades presenciais, com
ênfase nas atividades propostas na web.

Assim, neste modelo de educação a distância a mediação pedagógica do professor e do tutor são indispensáveis para o bom andamento do curso. Os encontros presenciais nos polos são um apoio importante para os estudantes sanarem suas dúvidas com os tutores presenciais e também estabelecerem vínculos com os colegas por meio de grupos de estudos.

\section{Desvendando a paisagem}

Para conhecer a realidade socioeconômica dos estudantes, tomouse como base o parâmetro de aptidão 


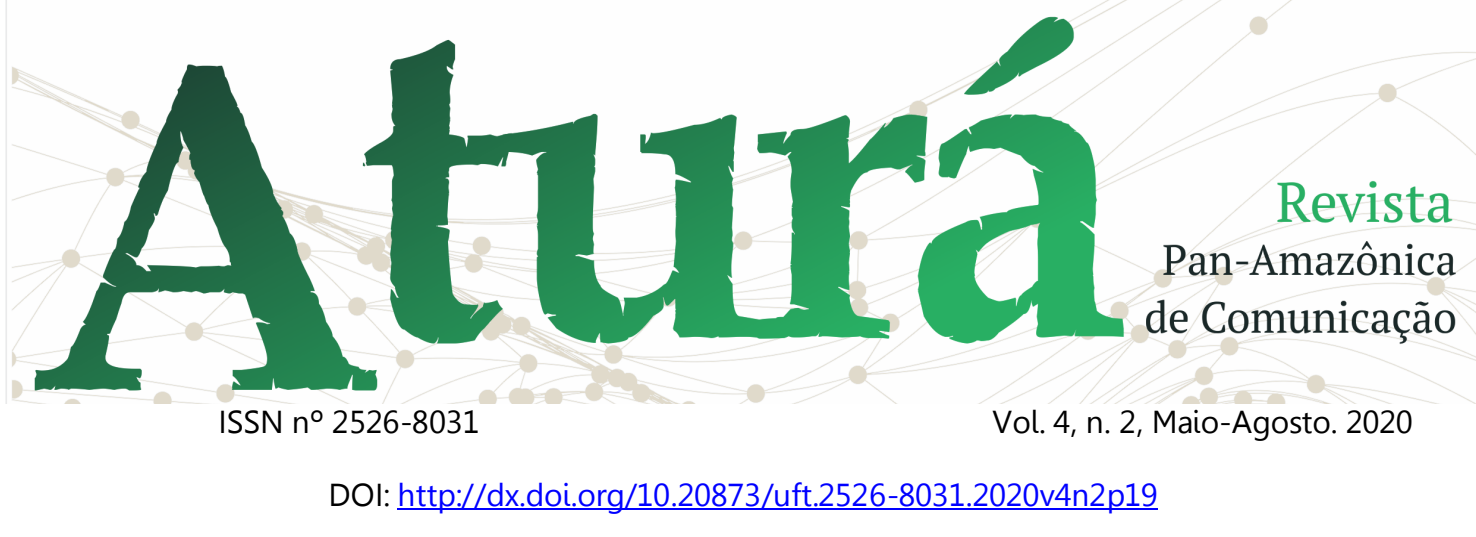

para receber o auxílio emergencial do governo federal de $R \$ 600,00$ (seiscentos reais) destinados a desempregados, trabalhadores informais, microempreendedores, contribuintes individuais do INSS, pessoas maiores de idade e que se encaixem nos requisitos de renda média mensal de até meio salário mínimo por pessoa ( $\mathrm{R} \$ 522,50)$; de até três salários mínimos por família ( $R \$$ 3.135,00), até 20 de março de 2020.

O Gráfico 1 a seguir, indica o quantitativo de estudantes que recebem o auxílio do Governo Federal.

Gráfico 1 - Recebimento do auxílio emergencial do Governo Federal

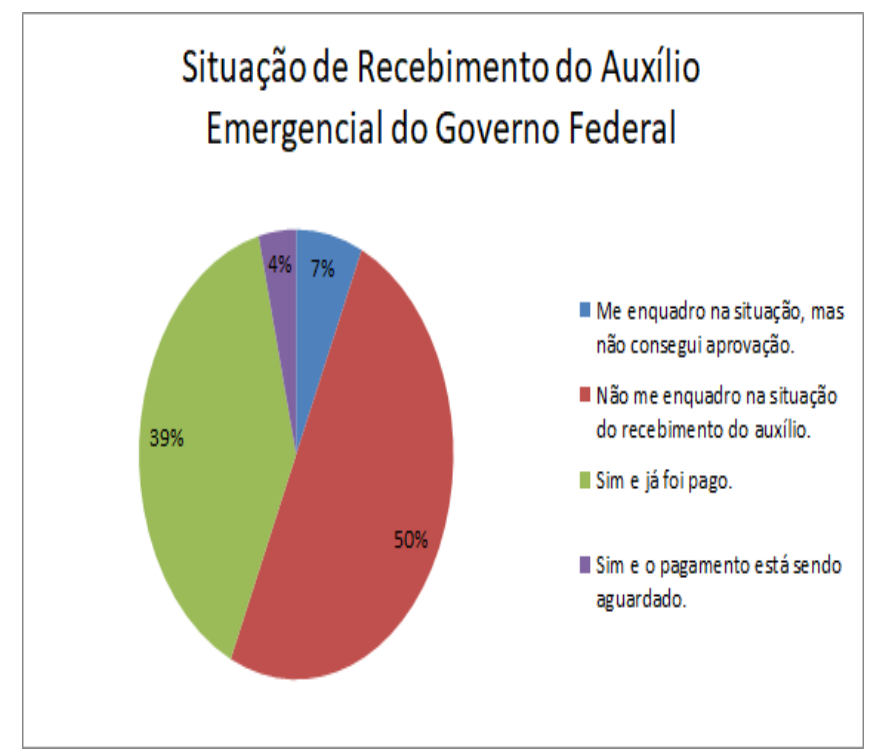

Fonte: Elaboração dos autores.

O gráfico apresenta dados que revelam que quase metade dos estudantes pertence ao grupo social que apresenta vulnerabilidade socioeconômica, o que retrata também a realidade tocantinense.

Ao se tratar das condições de trabalho e renda dos estudantes e suas famílias nesse período de pandemia, a realidade se mostra mais cruel, tanto assim que $60 \%$ dos respondentes indicam que foram afetados também economicamente (Gráfico 2).

Gráfico 2 - Condições de trabalho dos estudantes 


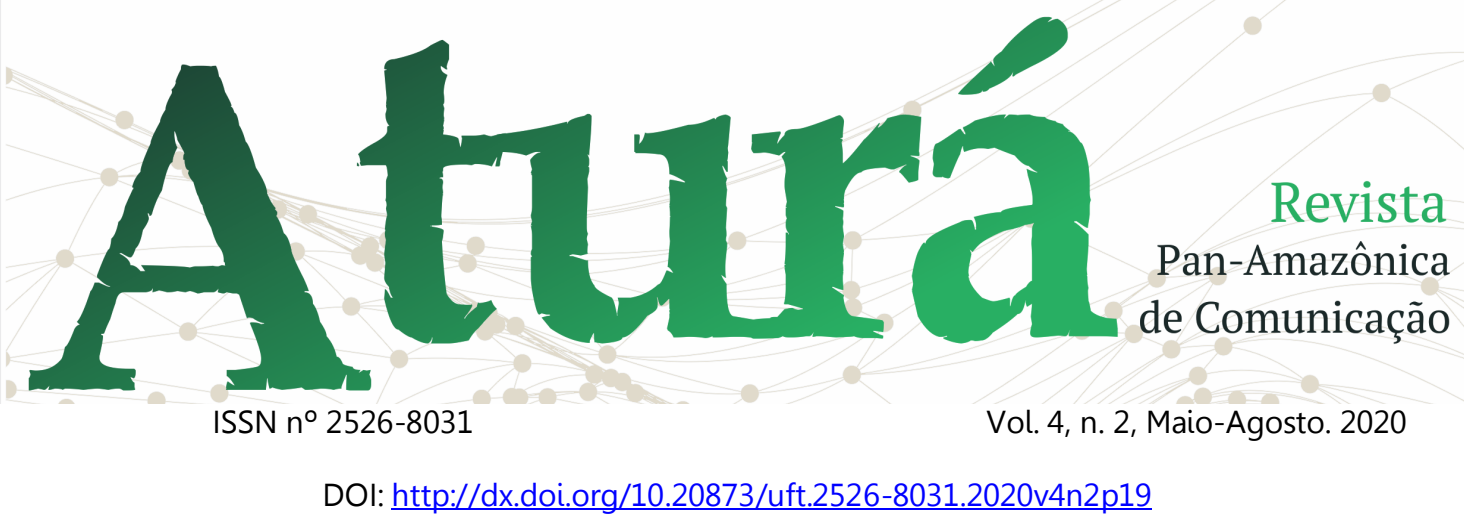

Impactos da Pandemia em Termos da Situação de Trabalho

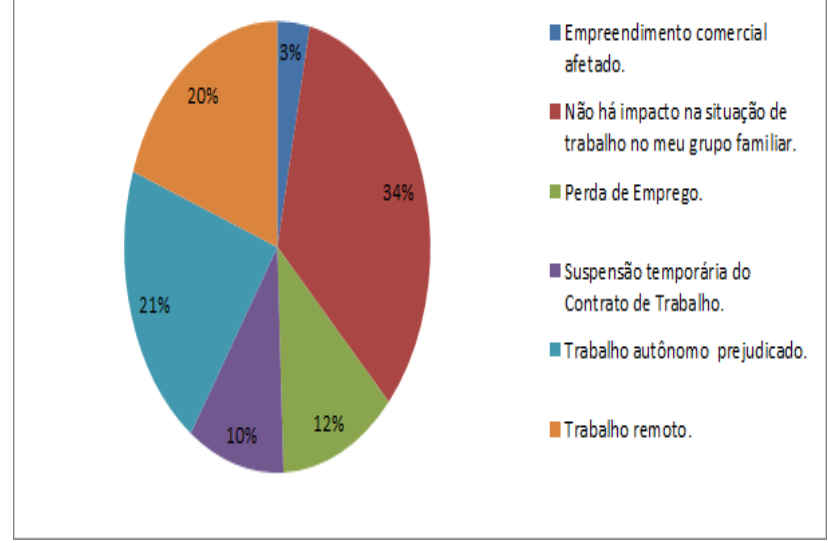

Fonte: Elaboração dos autores

Considerando que a maioria dos estudantes da $\mathrm{EaD}$ já são adultos e trabalham, a situação de emprego é uma variante importante para o sustento das suas famílias. Os dados revelam que apenas $34 \%$ afirmaram que não foram afetados em relação a seus empregos; $12 \%$ perderam o emprego; $21 \%$ informam que são autônomos e foram prejudicados com a crise gerada pela pandemia; $10 \%$ informaram que houve suspensão temporária de seus empregos; e 3\% sentem que o empreendimento comercial foi afetado. Os $20 \%$ restantes informaram que estão em trabalho remoto.
Os estudantes revelaram problemas de ordem econômica, emocional, sobrecarga de trabalho, o que pode ser visto de forma mais precisa no Gráfico 3, a seguir.

Gráfico 3 - Dificuldades relatadas pelos estudantes

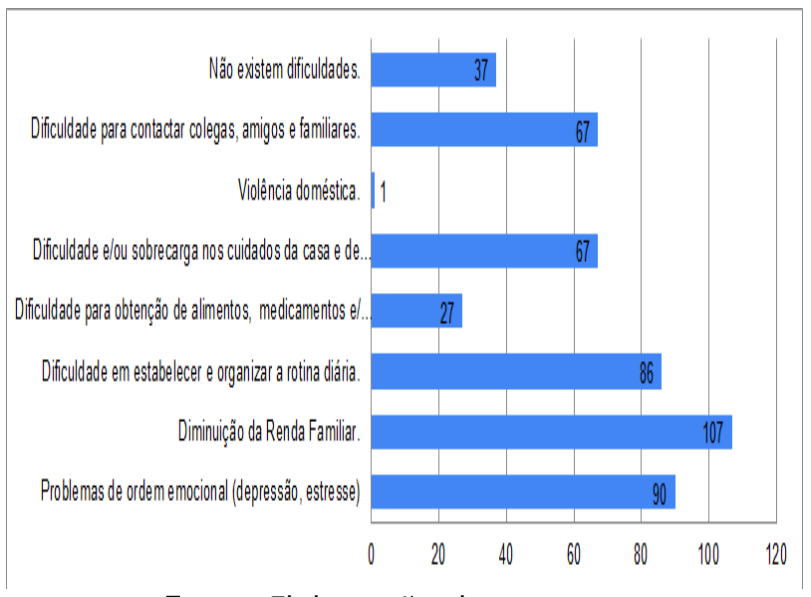

Fonte: Elaboração dos autores

Os dados mostram o quantitativo de pessoas que mencionam redução da renda familiar. Chama também à atenção as indicações de problemas emocionais, em organizar a rotina diária $e$ as dificuldades para contatar familiares. Registra-se 0 caso de violência doméstica.

$\mathrm{Na}$ continuidade perguntou-se se tais dificuldades afetavam de alguma forma seu desempenho nas atividades 


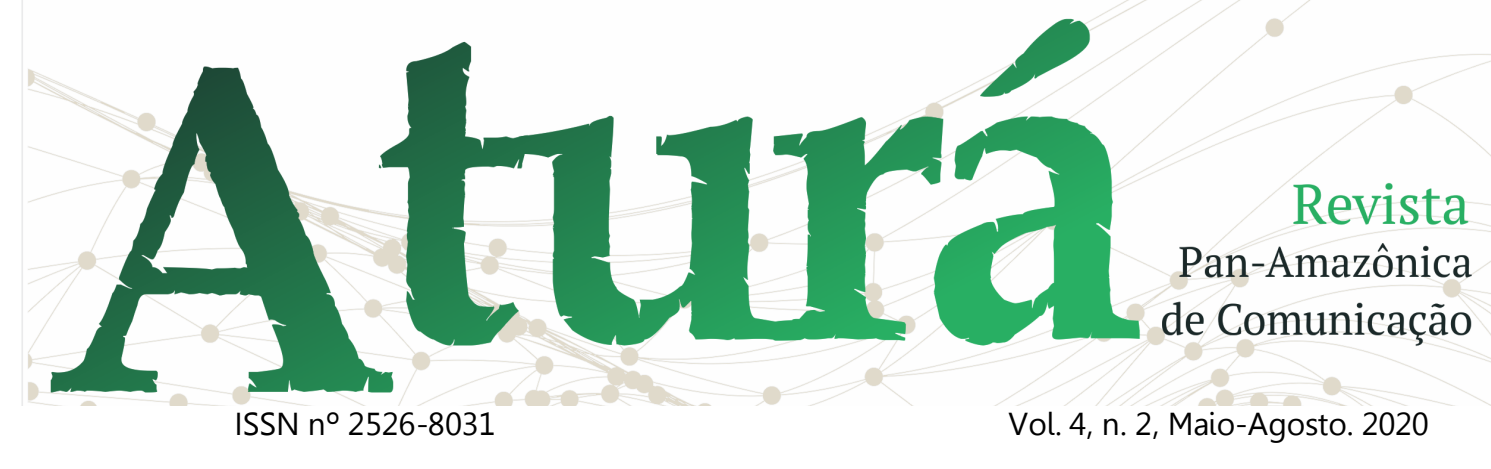

DOI: http://dx.doi.org/10.20873/uft.2526-8031.2020v4n2p19

acadêmicas. Dos 221 respondentes, 79 $(35,7 \%)$ responderam que não foram afetados, 20 (9\%) não responderam e 122 $(55,2 \%)$ responderam que sim. No Quadro 1 consta uma síntese das respostas com as respectivas indicações de situações vivenciadas.

Quadro 1 - Situações relatadas que implicam no desempenho das atividades acadêmicas

Sim. Estar em casa em home office trouxe dificuldades no alinhamento do meu cronograma e cumprimento das atividades.

Sim. Porque todos lá em casa estão tendo aula remota e só temos um computador, por isso veio a comprometer em alguns momentos devido ao volume de atividades.

Sim. Teve momentos de desespero, pânico, preocupações, medo e desânimo. Desistência de alguns cursos, mas agora estou tentando voltar ao controle.

Sim, por causa do medo, sai da minha casa e fui para o interior por mais de 60 dias.

Sim, durante esse período de calamidade na saúde pública a internet de minha região sobrecarregou. Devido a isso tenho dificuldade de acessar internet.

Sim, pois moro na área rural e não temos sinal de celular e nem internet.

Fonte: Elaboração dos autores.

Percebe-se que um número

considerável de estudantes está passando por problemas de diversas categorias que afetaram o seu desempenho acadêmico. A ansiedade e depressão foram relatadas por muitos participantes como fatores que levaram a falta de concentração e desânimo em relação aos estudos. Alguns estudos já realizados em população de estudantes do nível superior revelam que a ansiedade e a depressão afetam o desempenho acadêmico dos estudantes, levando até mesmo a desistência dos estudos (MONDARDO, PEDON, 2005; SILVA et. al, 2010; MIRANDA; REIS, FRETIAS, 2017). Numa situação de pandemia os níveis de depressão e ansiedade podem chegar a níveis muito maiores, conforme o seguinte estudo relata:

No curto período de tempo em que a pandemia se expandiu, ocorreu aumento da prevalência de Transtornos Mentais Comuns (TMC), especialmente fadiga e agressividade, estresse agudos, episódios de pânico, a manifestação de preditores de estresse pós traumático (TEPT), depressão e ansiedade, não apenas nos profissionais, mas na população, de modo geral. E essa prevalência é positivamente associada à exposição constante de notícias sobre a doença em mídias sociais. (CRUZ, et al, 2020, p.1)

Muitos estudantes com sintomas de sofrimento emocional encontram dificuldades em organizar sua agenda de estudos, se concentrarem nos afazeres e realizar a grande demanda de atividades 


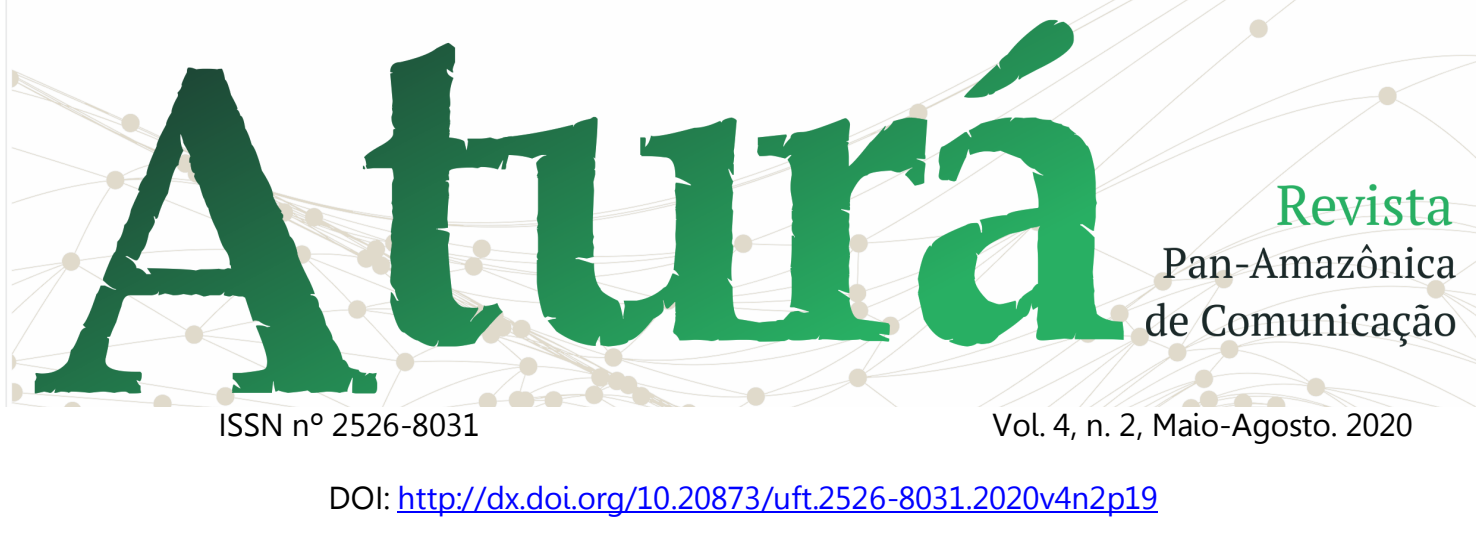

avaliativas do curso neste período de pandemia. O fechamento dos polos e a falta do tutor presencial também foi uma dificuldade relatada por vários estudantes. Alguns tiveram de se deslocar para cidades do interior ou campo em função do isolamento social e por consequência ficaram sem acesso à internet.

Ao questionamento se o estudante ou outra pessoa de seu grupo familiar conhece alguém que tenha recebido diagnóstico de Covid-19, do universo de 240 respondentes, $62 \quad(25,8 \%)$ responderam que não, 94 (39,2\%) mencionaram pessoa próxima e 80 $(33,3 \%)$ responderam que sim, mas de pessoa distante. Sobre a situação de saúde dos estudantes e dos familiares, $70 \%$ dos respondentes afirmaram ter na família pessoas que necessitam de cuidados especiais, o que impacta no aumento da carga de trabalho em casa, ansiedade ou medo de algum familiar contrair a doença e incerteza em relação ao futuro.

Em relação à situação de isolamento social do estudante e seus familiares, chama a atenção o fato de um número considerável precisar sair de casa em função da busca pela sobrevivência.

Gráfico 4 - Situação de isolamento social

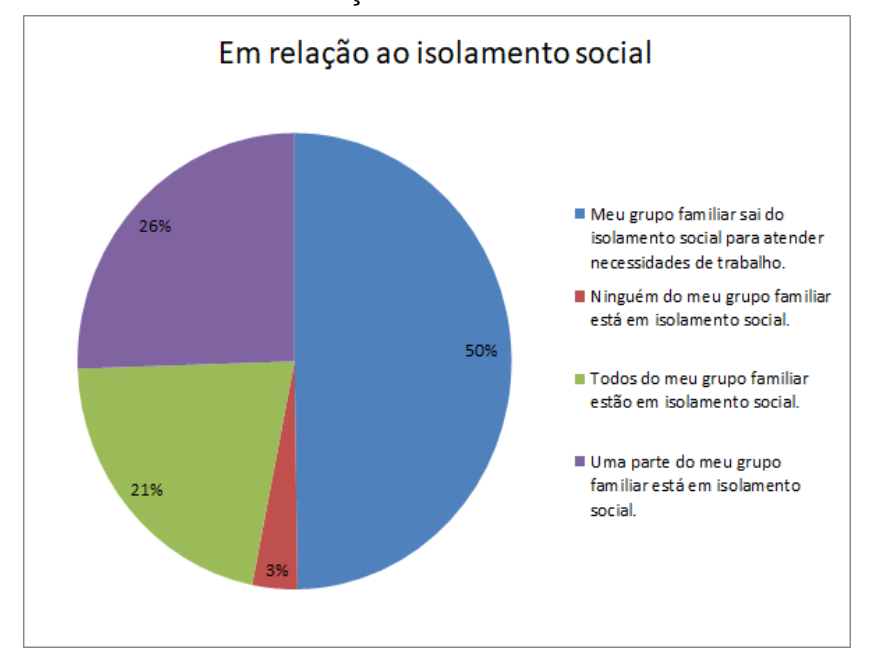

Fonte: Elaboração dos autores

As respostas dos estudantes

condizem com a realidade da maioria dos brasileiros, qual seja, precisam sair do isolamento social para atender às necessidades econômicas da família. De acordo com estudo realizado por Bezerra e associados (2020), no início da pandemia as pessoas aderiram bem ao isolamento social, mas a necessidade de 


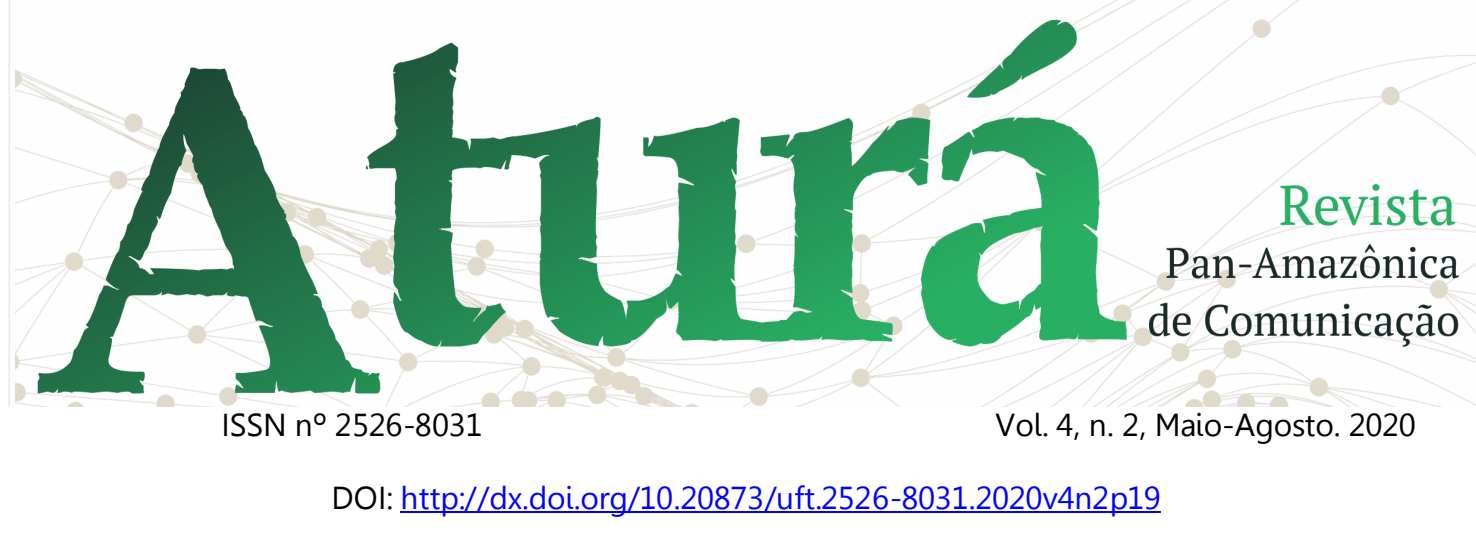

trabalhar e manter a família financeiramente não permitiu que todos do grupo familiar mantivessem 0 isolamento.

Ao sondar os estudantes em relação às implicações do isolamento social com seu desempenho no curso, as respostas seguem o parâmetro da questão que versa sobre as dificuldades enfrentadas pelos estudantes e familiares. De 229 respostas, 92 (40,2\%) estudantes afirmaram que o isolamento social não afetou seu desempenho acadêmico; 16 (7\%) não responderam, e 121 (52,8\%) disseram que foram afetados de alguma forma. Dentre as respostas dos estudantes que alegaram serem afetados, as razões eram em virtude da falta de acesso à internet, fechamento dos polos de apoio presencial, falta de concentração nos estudos devido a problemas financeiros, paralização dos estágios e dificuldades em realizar o Trabalho de Conclusão de Curso.

Embora os estudantes de graduação a distância da UFT já fizessem uso das tecnologias digitais, isso não

Gráfico 5 - Equipamentos de tecnologia dos estudantes

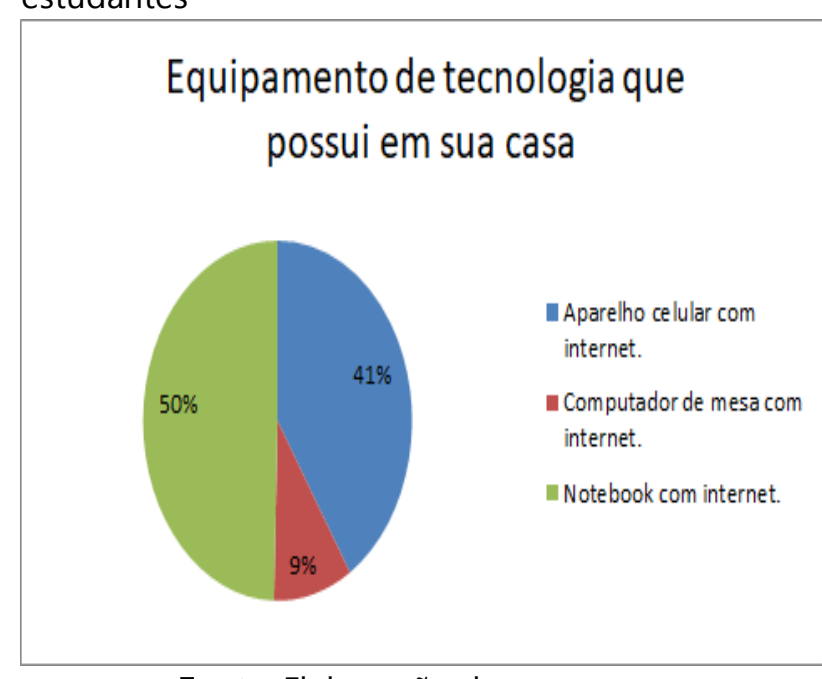

Fonte: Elaboração dos autores

Os dados revelam que $41 \%$ (um número considerável) acessam o material de estudo pelo celular e $50 \%$ deles possuem notebook com internet. Em relação ao local em que acessam a internet para realizar as atividades, 178 


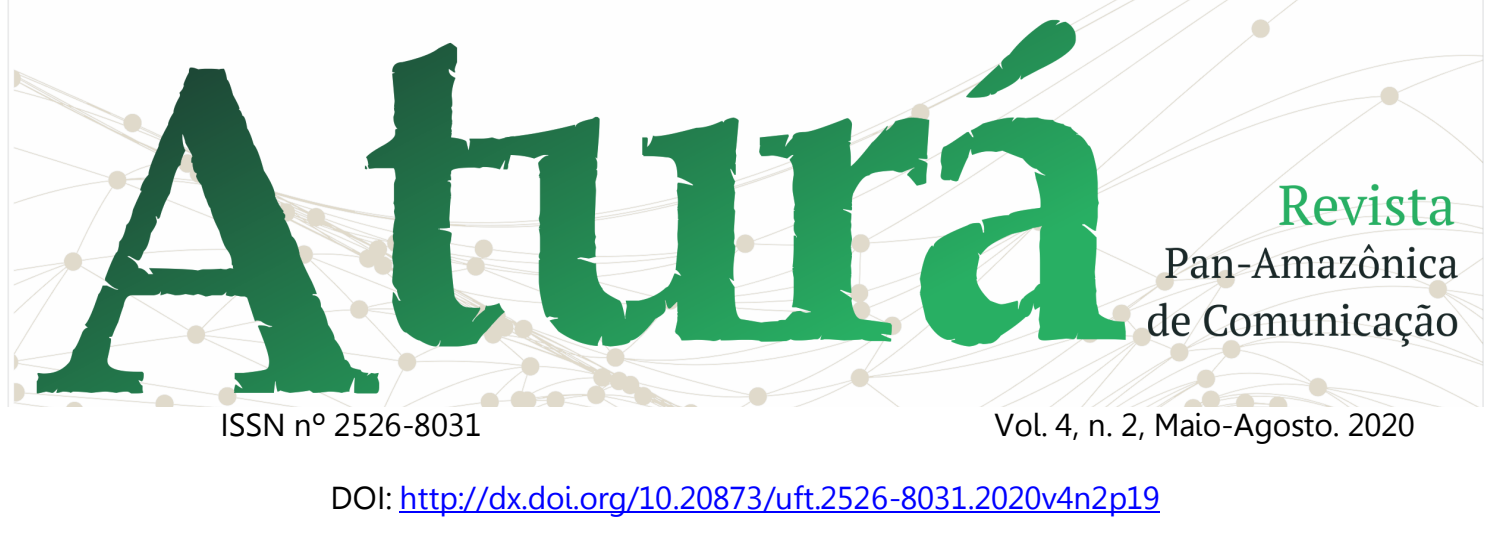

(74,5\%) estudantes disseram as Gráfico 6 a seguir apresenta uma síntese desenvolver em casa; 40 (16,7\%) o fazem pelo celular; e 15 (6,3\%) fazem as das respostas sobre o desenvolvimento e atividades online na casa de amigos ou familiares. Somente 6 (2,5\%) afirmam que faziam atividades exclusivamente no polo que neste momento encontra-se fechado e com atividades suspensas.

Ao serem questionados sobre as implicações do fechamento dos polos para seu rendimento acadêmico, a maioria (72\%) dos respondentes afirmou que não afetou o desenvolvimento de suas atividades e cerca de $20 \%$ disseram que foram pouco impactados, porque ocasionalmente compareciam ao local para realização de estudos. Os demais estudantes afirmaram que afetou sobremaneira porque faziam as atividades no polo.

Um pouco mais da metade dos estudantes, 50,8\% afirmaram que precisam compartilhar equipamentos tecnológicos com seus familiares e $41 \%$ deles disseram que não possuem um ambiente propício em casa para se concentrar e desenvolver os estudos. $\mathrm{O}$

Gráfico 6 - Situação dos estudantes quanto ao envio de atividades avaliativas

Realização de Atividades Avaliativas do Curso EaD

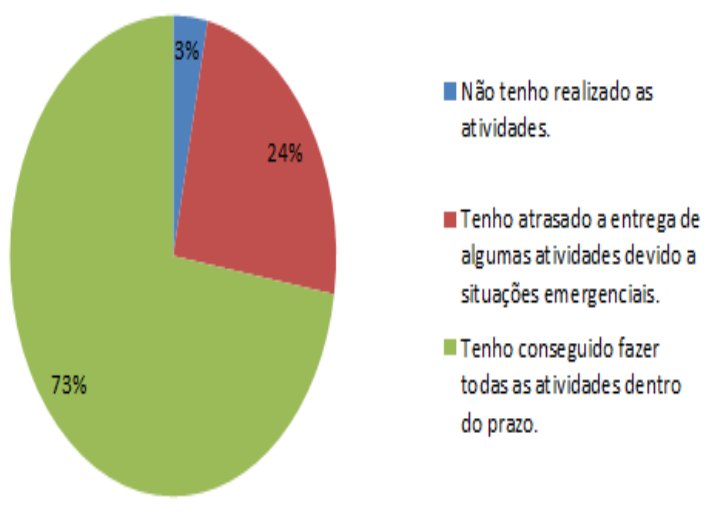

Fonte: Elaboração dos autores

Percebe-se que a maioria dos estudantes está conseguindo fazer as atividades e submetê-las dentro do prazo. Observa-se, no entanto, um número 


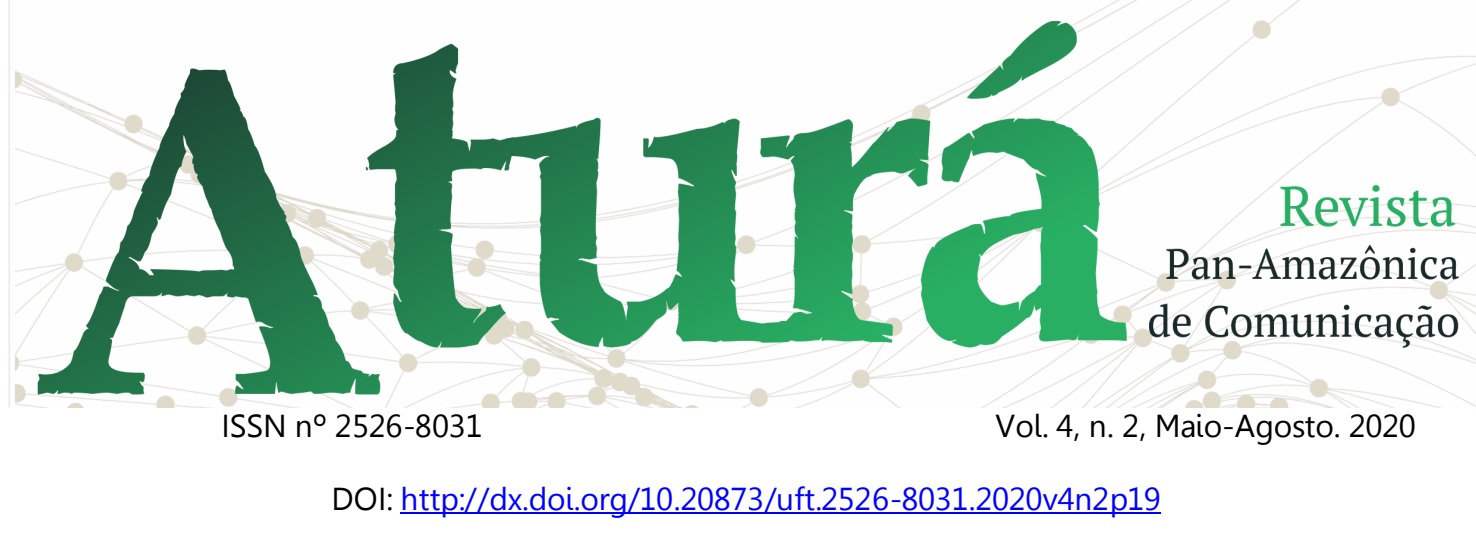

considerável (24\%) que atrasam a entrega das atividades e $3 \%$ que não as realizaram.

Os estudantes foram questionados sobre como avaliavam o acompanhamento das atividades pelos tutores, $51 \%$ consideram excelente e $33 \%$ avaliaram como um bom desempenho das atividades dos tutores. Observa-se, no entanto que $13 \%$ dos estudantes consideraram o atendimento razoável, $2 \%$ consideraram ruim e $1 \%$ julgam que é péssimo. Nas questões abertas do formulário sobre as dificuldades enfrentadas (questões 7 e 11), alguns estudantes alegaram sentir falta do acompanhamento mais sistemático do tutor, especialmente nesse momento crítico.

Considerando o conceito de presença social introduzido por Short Wiliams e Christie (1976) como uma qualidade que pode determinar a maneira como as pessoas interagem e se comunicam, o tutor que tem contato direto com os estudantes desempenha um papel importante na interação dos cursos. Enquanto responsáveis pela mediação no AVA (Ambiente Virtual de Aprendizagem), os tutores precisam promover junto aos estudantes o senso de pertencimento à comunidade e também estimular e promover a aprendizagem colaborativa entre eles (ALVES, MARTINS, 2017).

Registra-se que os professores das disciplinas também precisam estabelecer sua presença social, mantendo contatos com os estudantes no AVA e em horários previamente combinados para realizar chats, live, webconferência, dentre outras estratégias de ensino que permitam o diálogo entre estudantes e professores.

No contexto de pandemia, em que as pessoas estão mais sensíveis e com sentimentos de solidão, uma palavra acolhedora no fórum pode confortar os estudantes e ajudá-los a passar por este momento difícil sem comprometer fortemente seu rendimento acadêmico.

Os estudantes foram convidados a responder numa questão aberta o que pensam que poderia melhorar nos cursos a distância da UFT. Em síntese, pedem 


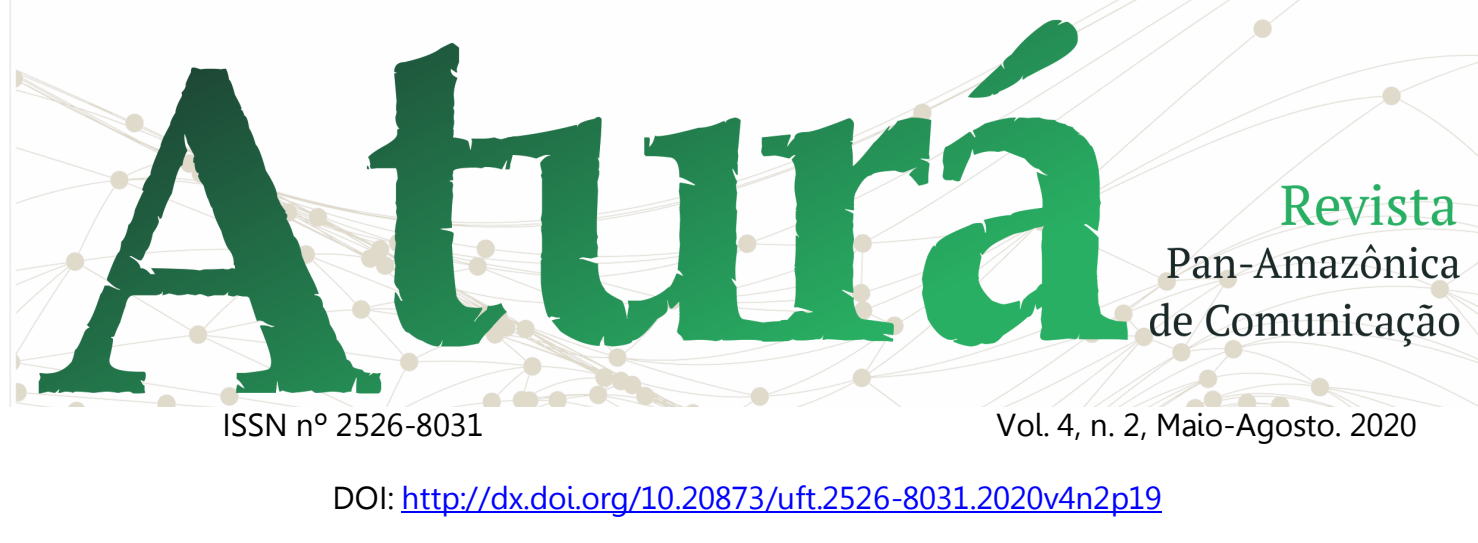

maior compreensão dos professores em relação ao volume de atividades. Também solicitaram mais tempo para realizar as atividades e um feedback de retorno dos testes realizados. Tendo em vista a grande quantidade de lives e reuniões por web conferência realizadas durante a pandemia, os estudantes também cobram este formato de comunicação junto aos professores e tutores. Outras questões como material didático de melhor compreensão, maior atenção da coordenação dos cursos e professores, e a disponibilidade de mais aulas em vídeo foram abordadas pelos estudantes como possíveis melhorias nos cursos.

Os estudantes também foram consultados em relação à necessidade de ajuda pedagógica ou psicológica. $74,7 \%$ dos estudantes dispensaram a ajuda e os demais deixaram contato (e-mail ou telefone) solicitando os serviços. Diante disso enviou-se e-mail a todos que deixaram o contato (22 estudantes).

Dentre às solicitações dos alunos, a maioria tratava-se de questões pontuais de ordem pedagógica do curso, as quais foram encaminhadas aos responsáveis dos cursos para serem solucionadas. Os e-mails que tratavam de solicitação de ajuda psicológica foram respondidos com mensagens positivas e encaminhamentos para ajuda do Serviço de Apoio Social, Pedagógico e Psicológico da UFT. Alguns estudantes (16) deixaram seu número de telefone (whatsapp). Esses também receberam o mesmo apoio dos relatados anteriormente via e-mail.

O que se percebe é que muitos estudantes estão passando por problemas emocionais e psicológicos como a maioria das pessoas no mundo, e muitas vezes tudo que precisam é de atenção. Querem ser lembrados, vistos, fazer parte de uma comunidade. E por vezes a EaD é um caminho solitário, o que demanda dos tutores e professores maior atenção de forma a tornar essa situação menos estressante.

\section{A paisagem e novos caminhos}

$O$ instrumento disponibilizado aos estudantes de EaD da UFT cumpriu o objetivo de conhecer sua realidade 


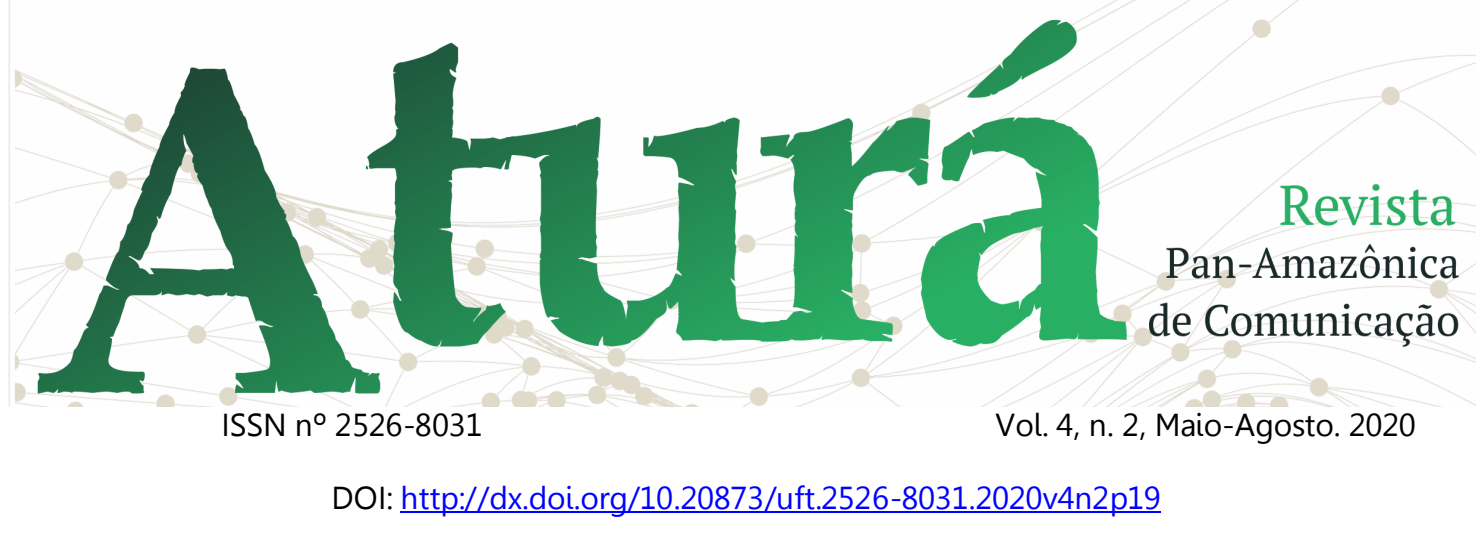

socioeconômica, de condições de saúde, de acesso aos meios tecnológicos e os reflexos da situação de pandemia no desempenho acadêmico dos mesmos.

Além de conhecer $\mathrm{O}$ perfil de acesso e uso de internet dos estudantes da EaD da UFT, mapeou-se aqueles que manifestaram sofrimento psicológico, a fim de encaminhá-los para atendimento especializado e garantir assistência pedagógica, caso as aceitem.

Ao revelar o contexto dos estudantes em EaD da UFT no transcurso dos meses iniciais da pandemia, o presente estudo também aponta para medidas que deverão ser adotadas no próximo semestre letivo, uma vez que a situação de isolamento social ainda perdurará. Informados da realidade diagnosticada, cabe à equipe gestora dos cursos, em especial aos coordenadores, articular junto aos professores e tutores de cada curso as estratégias a serem adotadas, tendo em vista melhorias e, em especial, um acolhimento dos estudantes neste período de tantas incertezas.

Diante deste quadro, a coordenação pedagógica da DTE junto com os coordenadores de cursos levantaram estratégias a curto, médio e longo prazo que possam atender aos estudantes neste momento crítico. Dentre elas citam-se:

- Coordenadores: orientados a acompanhar periodicamente as salas virtuais dos seus cursos, observando o engajamento dos tutores e professores nas aulas e também monitorar a evasão.

- Tutores: orientados a dar feedback em no máximo 24 horas e permanecerem disponíveis na rede web para serem contatados pelos estudantes. Precisam fazer um mapeamento dos alunos que estão ausentes no AVA ou que não estão fazendo as atividades.

- Professores orientados a ter maior medida de "presença social" nas suas respectivas disciplinas. Isso inclui se apresentar aos estudantes por vídeo ou web conferência, participar dos fóruns de discussão e disponibilizar tempo para interagir com os mesmos. Na situação de pandemia, professores necessitam ser 


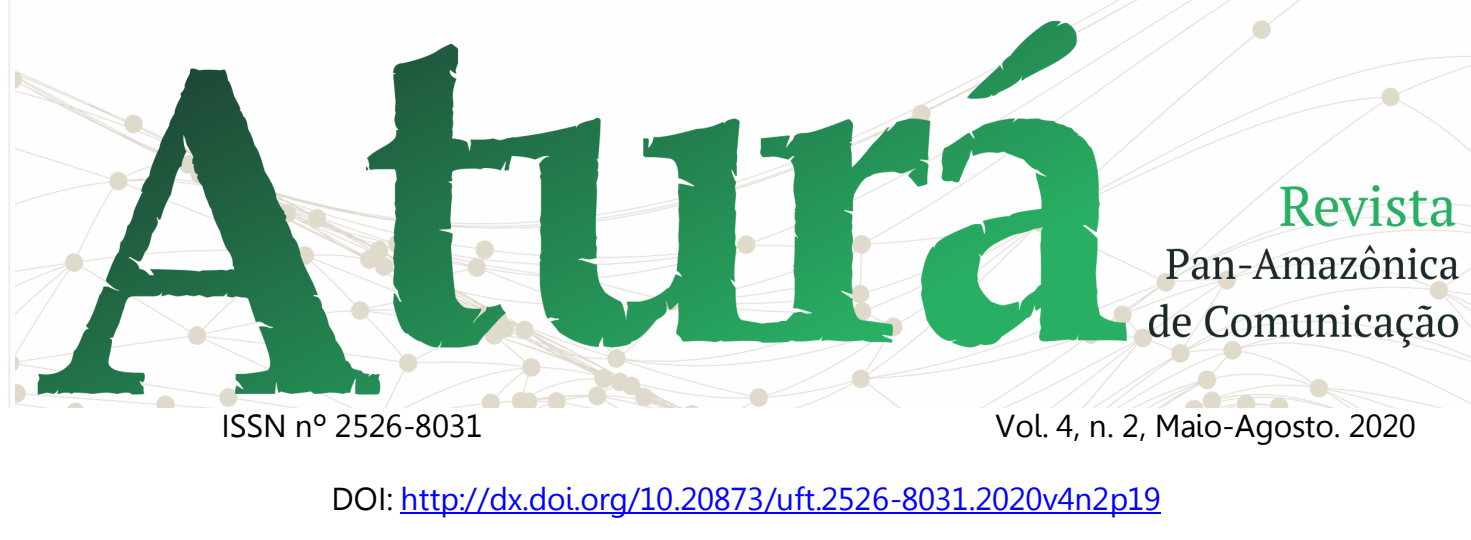

mais flexíveis com o número de atividades (redução) e os prazos de entrega (extensão).

Além destas ações foi proposta a formação de um grupo de estudos com participação dos professores da coordenação pedagógica (DTE), coordenadores de cursos, professores $\mathrm{EaD}$ e tutores para pesquisa e discussão sobre os novos formatos que a educação a distância vem se moldando diante da situação de pandemia.

Cada vez mais o modelo EaD se distancia do formato original baseado em conteúdos e via correspondência um para muitos. Hoje, com as tecnologias que permitem a comunicação síncrona em encontros simultâneos, a EaD molda-se no formato muito para muitos, ou seja, os estudantes deixam seu papel passivo de receptor de informações para pesquisador, coautor, colaborador e agente ativo da sua formação. Acredita-se que a compreensão destes avanços nos modelos de educação a distância poderão sensibilizar os professores e tutores a conduzir o processo educativo

com uma medida de presença social que previna a evasão, possibilite $\mathrm{O}$ engajamento dos estudantes, e por sua vez uma aprendizagem efetiva.

\section{Referências}

ALVES, E. J. MARTINS, J. L. Presença social dos mediadores em fórum virtual. Anais eletrônicos do $7^{\circ}$ Simpósio de Hipertexto e Tecnologia na Educação. Recife, Pernambuco, 2017. Disponível em: http://www.nehte.com.br/simposio/anais/ simposio2017.html . Acessado em 25 jun 2020.

ALVES, E. J.; FARIA, D. C. DE. EDUCATION IN TIMES OF PANDEMIC: Lessons learned and shared. Revista Observatório, v. 6, n. 2, p. a16en, 1 abr. 2020.

ALVES, E. J.; SILVA, B. D. DA. APRENDER "COM" A TECNOLOGIA: O uso do Facebook no processo de aprendizagem e interação de curso online. Revista Observatório, v. 5, n. 4, p. 658-669, 1 jul. 2019.

BECKER, F., \& MARQUES, T. B. Ensino ou aprendizagem à distância. Educar em Revista, 19, pp.85-98, 2002.

BEZERRA, A. C. V. et al . Fatores associados ao comportamento da população durante o isolamento social na pandemia de COVID-19. Ciênc. saúde coletiva, Rio de Janeiro, v. 25, supl. 1, p. 


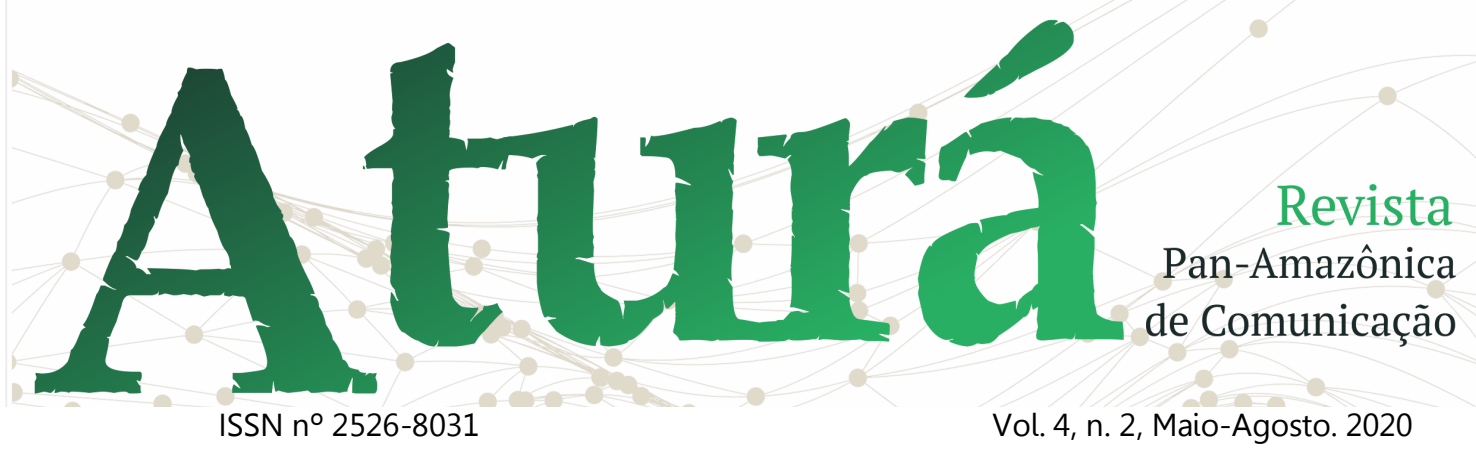

DOI: http://dx.doi.org/10.20873/uft.2526-8031.2020v4n2p19

2411-2421, Junho 2020. Disponível em: http://www.scielo.br/scielo.php?script=sci arttext\&pid=S1413$81232020006702411 \& \operatorname{lng}=$ en\&nrm=iso . Acessado em 26 Jun 2020.

COSTA, D. D. S. et al. Saúde Mental na pandemia de COVID-19: Considerações práticas multidisciplinares sobre cognição, emoção e comportamento. Debates em psiquiatria. Disponível em: https://www.researchgate.net/publication $\$ 341255949$ Saude mental na pandemia de COVID -

19 consideracoes praticas multidisciplina res sobre cognicao emocao e comporta mento Acessado em 24 jun 2020.

CRUZ, R. M. et al . COVID-19: emergência e impactos na saúde e no trabalho. Rev. Psicol., Organ. Trab., Brasília, v. 20, n. 2, p. I-III, jun. 2020 . Disponível em: http://pepsic.bvsalud.org/scielo.php?scrip $\mathrm{t}=$ sci arttext\&pid=S1984$66572020000200001 \& \operatorname{lng}=\mathrm{pt} \& \mathrm{nrm}=$ iso Acessado em 26 jun. 2020.

FARIA, D. C. DE; ALVES, E. J.; NUNES, S. G. DA C. EDUCAÇÃO A DISTÂNCIA DA UFT/UAB NA PERCEPÇÃO DOS DISCENTES. Revista Observatório, v. 5, n. 3, p. 166-187, 1 maio 2019.

GODOY, A. Schmidt. Pesquisa qualitativa: tipos fundamentais. Revista de Administração de Empresas. São Paulo, v. 35, n. 3, pp. 20-29 Mai./Jun. 1995

IBGE. Pesquisa Nacional por Amostra de Domicílios Contínua - PNAD Contínua.
Acesso à Internet e à televisão e posse de telefone móvel celular para uso pessoal, $2018 . \quad$ Disponível em: https://www.ibge.gov.br/estatisticas/socia is/trabalho/17270-pnadcontinua.html?edicao $=27138 \& \mathrm{t}=$ resultad s Acessado em 29 jun 2020.

LEJANO, R. Fraweworks for Policy Analises. Maging Text and Context. New York: Routledge, 2006.

MIRANDA, G. J.; REIS, C. F.; FRETIAS, S. C. Ansiedade e desempenho acadêmico: um estudo com alunos de ciências contábeis. In: XVII International conference in accouting. 2017. p. 1-14.

MONDARDO, A. H.; PEDON, E. A. Estresse e desempenho acadêmico em estudantes universitários. Revista de Ciências Humanas, v. 6, n. 6, p. 159-180, 2005.

SAINZ, I.,SAINZ J.,CAPILLA, A. Efeitos da crise COVID na educação. Organización de Estados Iberoamericanos para la Educación, la Ciencia y la Cultura (OEI). 2020.

SCHMIDT, B. et al . Saúde mental e intervenções psicológicas diante da pandemia do novo coronavírus (COVID19). Estud. psicol. Campinas , v. 37, e200063, 2020 . Disponível em: http://www.scielo.br/scielo.php?script=sci arttext\&pid=S0103$166 \times 2020000100501 \& \operatorname{lng}=$ en\&nrm $=$ iso Acessado em 25 Jun 2020. 


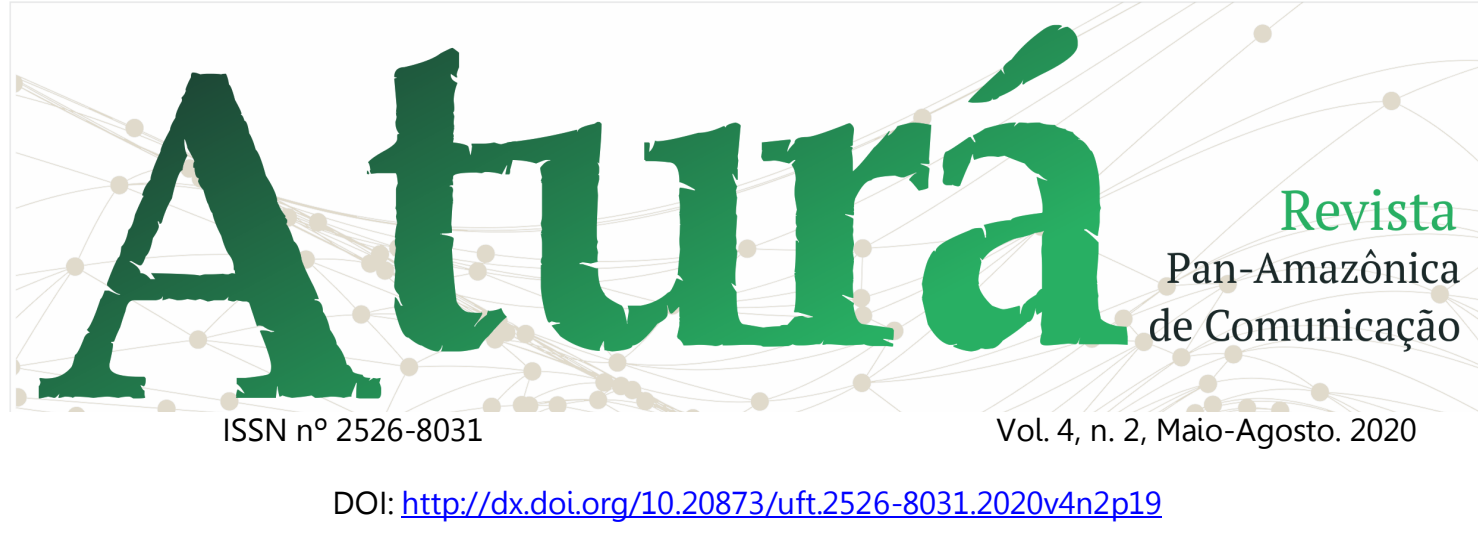

SILVA, G. C. C. et al. Ansiedade e depressão em residentes em Radiologia e Diagnóstico por Imagem. Revista Brasileira de Educação Médica, v. 34, n. 2, p. 199-206, 2010.

SILVA, B. D. DA; ALVES, E. J.; PEREIRA, I. C. A. DO QUADRO NEGRO AO TABLET: Desafios da docência na era digital. Revista Observatório, v. 3, n. 3, p. 532-560, 1 maio 2017.

SHORT, J., WILLIAMS, E., \& CHRISTIE, B. The social psychology of telecommunications. London: John Wiley \& Sons, 1976.

UFT. Projeto Pedagógico do curso de Licenciatura em Física a Distância. Palmas, 2009. 